\title{
Transformation of $\mathrm{SiO}_{x}$ films into nanocomposite $\mathrm{SiO}_{2}(\mathrm{Si})$ films under thermal and laser annealing
}

\author{
O.V. Steblova ${ }^{1}$, A.A. Evtukh ${ }^{1}$, O.L. Bratus, ${ }^{1}$, L.L. Fedorenko ${ }^{1}$, M.V. Voitovych ${ }^{1}$, \\ O.S. Lytvyn ${ }^{1}$, O.O. Gavrylyuk ${ }^{2}$, O.Yu. Semchuk ${ }^{2}$ \\ ${ }^{1} V$. Lashkaryov Institute of Semiconductor Physics, NAS of Ukraine, \\ 41, prospect Nauky,03028 Kyiv, Ukraine, e-mail: a.evtukh@i.ua \\ ${ }^{2}$ Chuiko Institute of Surface Chemistry, NAS of Ukraine \\ 17, General Naumov str., 03164 Kyiv, Ukraine; e-mail: oleksandr_gavrylyuk@mail.ru
}

\begin{abstract}
Oxide-assisted growth of Si nanocrystals includes deposition of a siliconenriched $\mathrm{SiO}_{\mathrm{x}}$ film at the first stage and annealing at the second one. The ion-plasma sputtering method has been used for deposition of the $\mathrm{SiO}_{\mathrm{x}}$ film. The influence of thermal and laser annealing on $\mathrm{SiO}_{\mathrm{x}}$ film properties has been investigated. Formation of silicon nanoislands on oxide film surface has been observed by AFM both after thermal and laser annealing. The height and surface density of the nanoislands depends both on the silicon content in the initial $\mathrm{SiO}_{\mathrm{x}}$ film and temperature of thermal annealing. The higher annealing temperature causes formation of large nanoislands, but their surface density decreases. Comparison of nanoislands created at thermal and laser annealing shows that in case of laser annealing the nanoislands are higher and their surface density is lower. The intensity of laser irradiation influences on nanoisland parameters significantly. The growth of electrical conductivity with thermal annealing temperature has been observed. The influence of gas atmosphere during annealing is also significant in case of higher temperatures. In case of laser annealing at the beginning at low laser irradiation intensities, the $\mathrm{SiO}_{\mathrm{x}}$ film conductivity increases, but the following growth of intensity causes the decrease in electrical conductivity.
\end{abstract}

Keywords: silicon nanoclusters, nanocomposite films, ion-plasma sputtering, thermal annealing, laser annealing, IR spectroscopy, AFM, electrical conductivity.

Manuscript received 22.01.14; revised version received 22.07.14; accepted for publication 16.09.14; published online 30.09.14.

\section{Introduction}

Formation of Si nanocrystals embedded in silicon oxide thin films has gained an increasing interest because of potential applications in optoelectronic and nanoelectronic devices. In fact, low dimensionality effects determine unique semiconductor structure properties, even at room temperature, allowing incorporation of optoelectronic functions into silicon integrated circuit technology, research and development of nanocrystal single-electron transistors, resonant-tunnel diodes and nanocrystal memory cells [1-5]. The floating gates consisting of silicon nanocrystals embedded in a silicon oxide layer have been proposed as an alternative to the use of polysilicon in nonvolatile memory in order to increase the storage density and reduce power consumption. Nowadays, there are the number of technologies for obtaining nanocomposite $\mathrm{SiO}_{2}(\mathrm{Si})$ films, and each of them has its advantages and disadvantages. In this context, several methods have been developed to prepare silicon enriched silicon oxide films at relatively low temperatures such as thermal evaporation [6,7], a low pressure chemical vapor deposition (CVD), photo-CVD and laser ablation [8-14]. But even in case of the laser ablation, as a 
rule, the following high temperature annealing is needed to form the Si nanocrystals due to low laser intensity in process of deposition and low adsorption coefficient of $\mathrm{SiO}_{\mathrm{x}}$ at used wavelength (for example $\alpha<10^{-6}$ at $\lambda<$ $532 \mathrm{~nm})$ [10].

In this work, the influence of thermal and local laser annealing on transformation of $\mathrm{SiO}_{\mathrm{x}}$ film into nanocomposite $\mathrm{SiO}_{2}(\mathrm{Si})$ film has been investigated experimentally. The idea is to use the laser and thermal annealing at the second stage of silicon nanocrystals formation and compare their influence on film parameters. Such advantages as annealing of local areas on the substrate and temperature gradient control through the film can be realized in case of laser annealing $[15,16]$. AFM images, IR-spectra and electrical conductivity of thermal and laser-annealed $\mathrm{SiO}_{\mathrm{x}}$ films have been used as the main investigated characteristics.

\section{Experiment}

The $\mathrm{SiO}_{\mathrm{x}}$ films were deposited on $n$-type silicon wafer ( $\rho=4.5 \mathrm{Om} \cdot \mathrm{cm}(100))$ using an ion plasma sputtering (IPS) method [17]. The silicon target was sputtered using argon ions in the environment of $\mathrm{Ar}+\mathrm{O}_{2}$. The gas ratio during film deposition $\mathrm{Ar} / \mathrm{O}_{2}$ was changed at deposition to obtain $\mathrm{SiO}_{\mathrm{x}}$ films with different content of excess silicon. Other deposition parameters were as follows: pressure during the deposition process $P=$ $=8 \cdot 10^{-4}$ Torr, substrate temperature $T=150^{\circ} \mathrm{C}$, heating cathode current $I_{C}=145 \mathrm{~A}$, anode voltage $V_{A}=50 \mathrm{~V}$, anode current $I_{A}=10-11 \mathrm{~A}$, voltage on target $V_{T}=$ $1.1 \ldots 1.3 \mathrm{kV}$, deposition current $I_{S}=0.65 \mathrm{~mA}$. The deposited $\mathrm{SiO}_{\mathrm{x}}$ films thicknesses were within the range 50 to $150 \mathrm{~nm}$. During the ion plasma sputtering process, partial oxidation of silicon atoms is realized, and the proportion of oxidized atoms depends on the $\mathrm{O}_{2} / \mathrm{Ar}$ gas ratio. The $\mathrm{SiO}_{\mathrm{x}}$ films with different content of excess silicon $(x)\left(N_{1}(x=0.8)>N_{2}(x=1.1)>N_{3}(x=1.3)\right)$ were deposited.

Transformation of $\mathrm{SiO}_{x}$ film into nanocomposite $\mathrm{SiO}_{2}(\mathrm{Si})$ film was reached using thermal and laser annealing. The influence of thermal annealing on transformation of silicon-enriched $\mathrm{SiO}_{\mathrm{x}}$ films into nanocomposite $\mathrm{SiO}_{2}(\mathrm{Si})$ films was performed at different temperatures $\left(T=1000,1050\right.$ and $\left.1100{ }^{\circ} \mathrm{C}\right)$ for $30 \mathrm{~min}$ in nitrogen or argon atmosphere. Laser irradiation was carried out at room temperature and atmospheric pressure. The samples with the $\mathrm{Si} / \mathrm{SiO}_{\mathrm{x}}$ structures were irradiated from the $\mathrm{SiO}_{\mathrm{x}}$ side using the fundamental $(\lambda=1064 \mathrm{~nm}, t=10 \mathrm{~ns})$ and second harmonic $(\lambda=$ $532 \mathrm{~nm}, t=10 \mathrm{~ns}$ ) frequencies of the YAG: $\mathrm{Nd}^{+3}$ laser in Q-modulation mode with the intensity within the range from 10 to $112 \mathrm{MW} / \mathrm{cm}^{2}$. The range of intensities was chosen for reasons to achieve nondestructive annealing of $\mathrm{SiO}_{\mathrm{x}}$ layer by using the $\mathrm{Si}$ substrate as a heat source. Laser irradiation with the used wavelength isn't absorbed by $\mathrm{SiO}_{\mathrm{x}}$ film but mainly by $\mathrm{Si}$, and in such a way it heats the substrate. In that case, the Si substrate is a heat source for the film. $\mathrm{SiO}_{\mathrm{x}}$ surface was irradiated by the single-mode focused laser beam with computercontrolled scanning at the repetition frequency $25 \mathrm{~Hz}$ and adjustable degree of overlapping with the laser spot close to 0.3 . The level of the laser beam intensity was governed by defocusing and/or by the optical neutral grey filters. The pulsed laser energy and duration were measured using the conventional pulsed energy meter and coaxial photo-element FC-19 with the oscilloscope C8-12, accordingly.

IR spectra of the films were measured within the range 800 to $1400 \mathrm{~cm}^{-1}$ by using the Fourier spectrometer Spectrum BX (firm Perkin-Elmer). As the reference sample for comparison, a clean silicon substrate without film was used.

Also, AFM was used to check surface topology of $\mathrm{SiO}_{2}(\mathrm{Si})$ films annealed by thermal or laser irradiation.

The metal-insulator-semiconductor (MIS) $\mathrm{Al} / n$ $\mathrm{Si} / \mathrm{SiO}_{2}(\mathrm{Si}) / \mathrm{Al}$ structures with oxide films both initial and annealed were formed. Aluminum gates were obtained using the magnetron sputtering of Al target. The circle capacitors with the area $7 \cdot 10^{-3} \mathrm{~cm}^{2}$ were formed via Al deposition through a metal mask. Solid aluminum layer was also deposited onto the back side of wafer. The measurements of current-voltage (I-V) characteristics were carried out using the automated complex including the controlled voltage source Keithley-2410. A personal computer was used to control the process. All electrical measurements were carried out in the dark at room temperature.

\section{Results and discussion}

\subsection{Thermal annealing}

Surface morphology. Atomic-force microscopy (AFM) was used to analyze the surface structure. The AFM morphology image of the initial $\mathrm{SiO}_{\mathrm{x}}$ film obtained by ion-plasma sputtering is shown in Fig. 1a. It is sufficiently homogeneous surface $(\mathrm{RMS} \approx 0.18 \mathrm{~nm})$ formed with small grains of up to the 0.4-nm height. As a result of high temperature annealing at $T=1000{ }^{\circ} \mathrm{C}$ and $1100{ }^{\circ} \mathrm{C}$ for $30 \mathrm{~min}$ of the sample with the silicon concentration $N_{3}(x=1.3)$, surface morphology changes with appearance of nanoinclusions (Figs. $1 \mathrm{~b}$ and 1c). Annealing at the temperature $1000{ }^{\circ} \mathrm{C}$ stimulated formation of nanoislands with the $0.8-\mathrm{nm}$ height at their surface density $n \approx 4 \cdot 10^{10} \mathrm{~cm}^{-2}$. After annealing at the higher temperature $\left(1100{ }^{\circ} \mathrm{C}\right)$, the density of islands didn't change, but their height increased up to $1.1 \mathrm{~nm}$. Behavior of the sample with the silicon concentration $\mathrm{N}_{2}$ $(x=1.1)$ demonstrates that annealing at $T=1050{ }^{\circ} \mathrm{C}$ leads to formation of two types of nanoislands on the surface, namely: the smaller ones with the $0.3 \ldots 1.0-\mathrm{nm}$ height and surface density $n \approx 4 \cdot 10^{10} \mathrm{~cm}^{-2}$ and higher ones with the height $1.0 \ldots 1.5 \mathrm{~nm}$ and density close to $1.2 \cdot 10^{10} \mathrm{~cm}^{-2}$. The higher annealing temperature $T=$ $1100{ }^{\circ} \mathrm{C}$ leads to formation of homogeneous but wider nanoislands. Their height decreased down to $0.4 \ldots 0.7 \mathrm{~nm}$. 

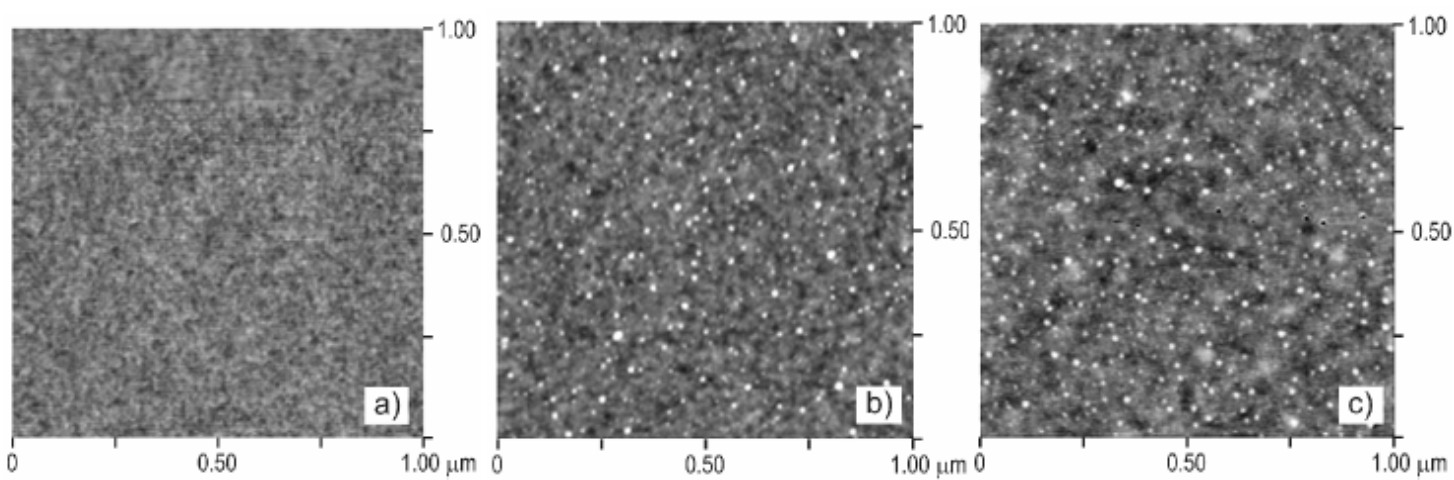

Fig. 1. AFM images of film surfaces $\left(N_{3}(x=1.3)\right)$ : initial $\mathrm{SiO}_{\mathrm{x}}(a)$; annealed at temperatures $1000{ }^{\circ} \mathrm{C}(b)$ and $1100{ }^{\circ} \mathrm{C}(c)$.

There is also a significant reduction in nanoislands density (down to $n \approx 8 \cdot 10^{9} \mathrm{~cm}^{-2}$ ). AFM images of samples with the silicon concentration $N_{1}(x=0.8)$ show that the height of nanoinclusions lies within 2.1..2.6 nm and RMS is $0.35 \mathrm{~nm}$. The periodic contact mode AFM pointed out on the another chemical composition of the nanoislands concerning the main surface [17]. The visual increase of the lateral size inherent to nanoislands is explained by the broadening effect of AFM topographic images, which depends on the curvature radius of the probe top ( $R=10 \mathrm{~nm}$, in our case).

Thus, thermal annealing leads to formation of the nanoislands with other chemical composition, namely, silicon on the background of the original surface $[18,19]$. Comparing the influence of the quantity of enriched silicon in initial $\mathrm{SiO}_{\mathrm{x}}$ films on formation of relief due to high temperature annealing, it is possible to conclude that the higher concentration of silicon in the initial films, the larger islands are formed, but their density decreases.

Infrared spectroscopy. The method of IR spectroscopy allows to characterize the composition and structure of the oxide matrix. The infrared transmission spectra of initial sample with the silicon concentration $N_{1}(x=0.8)$ (curve 1$)$ and annealed at the temperature $T=1100{ }^{\circ} \mathrm{C}$ (curve 2) of silicon oxide films are presented in Fig. 2. As it can be seen, the main IR absorption band of $\mathrm{SiO}_{\mathrm{x}}$ film with the maximum position at $v_{M 1}=1026 \mathrm{~cm}^{-1}$ after annealing noticeably shifts to the high frequency region (to $v_{M 2}=1076 \mathrm{~cm}^{-1}$ ), being twice increased in its area. This behavior is mainly associated with the change in phase composition of silicon oxide due to high temperature annealing [20,21]. It is possible to evaluate the content of deposited $\mathrm{SiO}_{x}$ films from the position of transmission band maximum $v_{M}$ for given technology according to the expression [22]:

$v_{M}=(987+48.8 x)$.

It was established that the stoichiometry index $(x)$ of the initial $\mathrm{SiO}_{x}$ film investigated using IR spectroscopy was $x \approx 0.8$, while after annealing it became $x \approx 1.82$.

To describe transformation in the $\mathrm{SiO}_{\mathrm{x}}$ structure after annealing, the IR spectra were rebuilt in the optical density spectra [17]. The optical density spectra of the initial and annealed films were mathematically decomposed into elementary components with Gaussian profiles, according to the method proposed in [23]. The obtained results show that the main absorption band of the initial $\mathrm{SiO}_{\mathrm{x}}$ film is the sum of seven subbands resulting from transverse (TO mode) and longitudinal (LO mode) valence fluctuations of bridging oxygen that is the part of the molecular complexes $\mathrm{Si}-\mathrm{O}_{\mathrm{y}}-\mathrm{Si}_{4-\mathrm{y}}$ $(1 \leq y \leq 4)$. The main contribution to the IR absorption band of initial film is given by the subbands $2,3,4$, which correspond to complexes of unoxidized silicon ( $\mathrm{Si}-\mathrm{O}-\mathrm{Si}_{3}, \quad \mathrm{Si}-\mathrm{O}_{2}-\mathrm{Si}_{2}, \quad \mathrm{Si}-\mathrm{O}_{3}-\mathrm{Si}$ ). The contribution of subband $5\left(\mathrm{SiO}_{4}\right)$ to the total area of the band is negligible. The subbands 6 and 7 are associated with longitudinal fluctuations of valence (LO) Si-O bond. As a result of annealing of the initial silicon-enriched $\mathrm{SiO}_{\mathrm{x}}$ $(x \approx 0.8)$ film, its transformation into the film $\mathrm{SiO}_{\mathrm{x}}$ with the stoichiometric index $x \approx 1.82$ is realized, and redistribution of intensities of elementary bands is observed. The integrated intensity of the subband associated with $\mathrm{Si}-\mathrm{O}-\mathrm{Si}_{3}$ complexes decreases by 6.5 times, and subbands associated with the $\mathrm{Si}-\mathrm{O}_{2}-\mathrm{Si}_{2}, \mathrm{Si}-$ $\mathrm{O}_{3}-\mathrm{Si}$ complexes disappear. The relative area of subbands caused by $\mathrm{Si}-\mathrm{O}$ TO vibration modes from the $\mathrm{SiO}_{4}$ tetrahedron combined into 4- and 6-fold rings is approximately $68 \%$, and the area of $\mathrm{Si}-\mathrm{O}-\mathrm{Si}$ subband is $14.6 \%$ of the total spectrum area indicating formation of $\mathrm{SiO}_{2}$ phase regions. The $\mathrm{Si}-\mathrm{O}-\mathrm{Si}_{3}$ complexes are available in the film after heat treatment. It indicates incomplete phase separation caused by annealing. It means the existence of $\mathrm{SiO}_{x}$ phase associated with a transition layer between $\mathrm{Si}$ nanoparticles and $\mathrm{SiO}_{2}$ matrix. For a complete description of the spectra, the band $965 \mathrm{~cm}^{-1}$ was also used. It is caused by $\mathrm{Si}-\mathrm{O}-\mathrm{Si}$ complexes in a-Si:H [23]. Its appearance in the initial $\mathrm{SiO}_{\mathrm{x}}$ film relates to the presence of water vapor or hydrogen in the operation gas during deposition. 


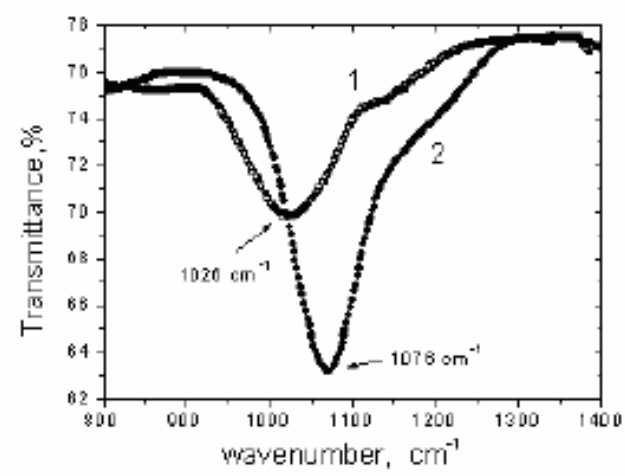

Fig. 2. IR transmission spectra of silicon oxide films in the following states: initial (1) and annealed (2) ones at $T=$ $1100{ }^{\circ} \mathrm{C}$ for $30 \mathrm{~min}$ in ambient $\mathrm{N}_{2}\left(N_{1}(x=0.8)\right)$.

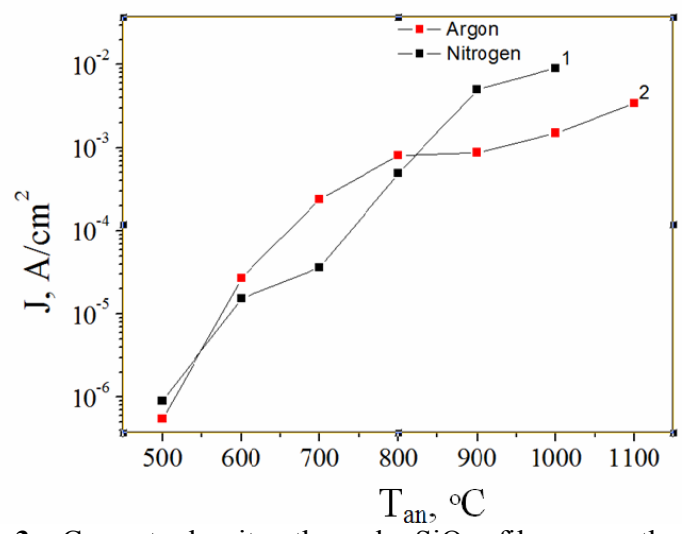

Fig. 3. Current density through $\mathrm{SiO}_{x}$ films on thermal annealing temperature dependences: $(1)$ annealing in nitrogen, (2) annealing in argon $\left(E=1 \cdot 10^{5} \mathrm{~V} / \mathrm{cm}\right)$.
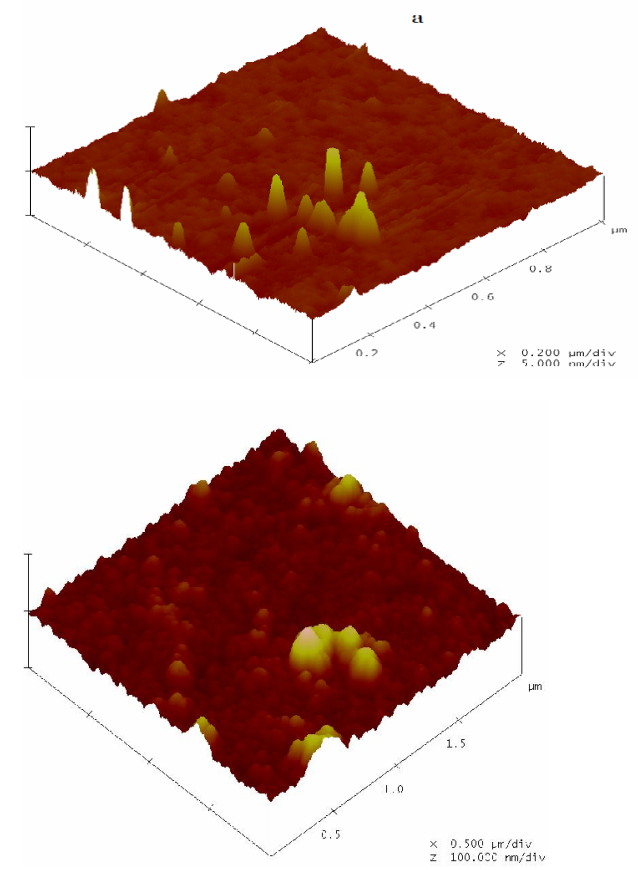

Thus, the heat treatment of $\mathrm{SiO}_{\mathrm{x}}$ films causes the decay of molecular complexes of weakly oxidized silicon and promotes formation of Si clusters and heavily oxidized silicon dioxide matrix.

Electrical conductivity. Current-voltage characteristics of $\mathrm{SiO}_{\mathrm{x}}$ film have two different regions. In the first one (until $E=5 \cdot 10^{4} \mathrm{~V} / \mathrm{cm}$ ), intense growth of current with increasing the electric field is observed, but in the second region at higher electric fields current saturation is realized. $I-V$ characteristics of $\mathrm{SiO}_{\mathrm{x}}$ films after thermal annealing at various temperatures show growth of current density with the increase of annealing temperature (Fig. 3). As it can be seen, both annealing in nitrogen and that in argon cause the increase of the current and, consequently, growth of electrical conductivity. This growth of electrical conductivity with temperature of annealing is caused by generation of electron traps in the oxide film during its transformation from $\mathrm{SiO}_{x}$ into $\mathrm{SiO}_{2}$ with $\mathrm{Si}$ nanocrystals. The higher conductivity of the nitrogen-annealed films at $T=$ $900 \ldots 1100{ }^{\circ} \mathrm{C}$ indicates the role of nitrogen in creation of electron traps in the oxide bandgap and at $\mathrm{Si}$ nanocrystal $-\mathrm{SiO}_{\mathrm{x}}$ interfaces.

\subsection{Laser annealing}

Surface morphology. Laser annealing in dependence on the light intensity leads to the local formation of nanoislands with different heights and surface density. But there is a lower intensity limit for formation of $\mathrm{Si}$ nanoislands, $I \approx 10 \mathrm{MW} / \mathrm{cm}^{2}$, and at the intensities
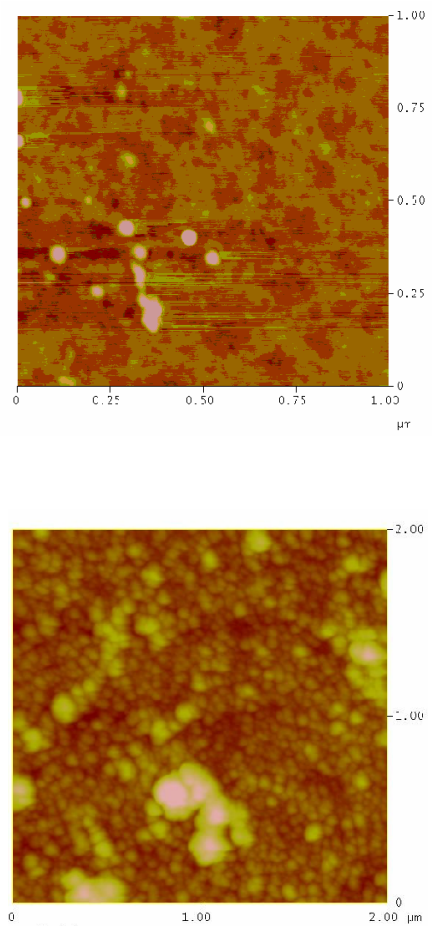

Fig. 4. AFM image of films topographies after annealing with (a) $I=17 \mathrm{MW} / \mathrm{cm}^{2}, \lambda=1064 \mathrm{~nm}$ and (b) $I=12.4 \mathrm{MW} / \mathrm{cm}^{2}, \lambda=$ $532 \mathrm{~nm}$. 
higher than $I=100 \mathrm{MW} / \mathrm{cm}^{2}$ the destructive changes on the film surface are observed. Laser annealing of the $\mathrm{SiO}_{\mathrm{x}}$ films for the laser wavelengths $\lambda=1064 \mathrm{~nm}$ and $532 \mathrm{~nm}$ in the range of intensities $I=10 \ldots 112 \mathrm{MW} / \mathrm{cm}^{2}$ has been investigated. Fig. 4 shows the AFM images of the surface morphology after laser annealing with $I=$ $17 \mathrm{MW} / \mathrm{cm}^{2}$ for $\lambda=1064 \mathrm{~nm}$ and $I=12.4 \mathrm{MW} / \mathrm{cm}^{2}$ for $\lambda=532 \mathrm{~nm}$. As it can be seen, laser annealing at the intensity $17 \mathrm{MW} / \mathrm{cm}^{2} \quad(\lambda=1064 \mathrm{~nm})$ led to local formation of $h=5 \mathrm{~nm}$ height nanoislands. Annealing by laser with $\lambda=532 \mathrm{~nm}$ caused formation of higher nanoislands. Their heights were within the range $30 \ldots 90 \mathrm{~nm}$ and dependent on the laser beam intensity. As a rule, the height of the nanoislands grows with increasing the laser intensity. On the contrary, the nanoislands density decreases with irradiation intensity growth.

The comparison of nanoislands created at thermal and laser annealing shows that in case of laser annealing the nanoislands are higher and their surface density is lower.

Infrared spectroscopy. The infrared transmission spectra of the initial sample with the silicon concentration $N_{1}(x=0.8)$ and laser annealed silicon oxide films with the light intensity $I=22 \mathrm{MW} / \mathrm{cm}^{2}$ for $\lambda=532 \mathrm{~nm}$ didn't show any shift of transmission minimum position $\left(v_{M 1}=1026 \mathrm{~cm}^{-1}\right)$ in high-frequency region, but its area significantly increased (approximately by two times). Such IR spectra behavior is indicative of unsufficient transformation of oxide matrix. To obtain transformation of oxide $\mathrm{SiO}_{\mathrm{x}}$ matrix into $\mathrm{SiO}_{2}$ one, it is necessary to irradiate using a laser beam with higher intensities [24].

Electrical conductivity. The dependences for the density of current through the film on laser irradiation intensity with electric field as a parameter are shown in Fig. 5.

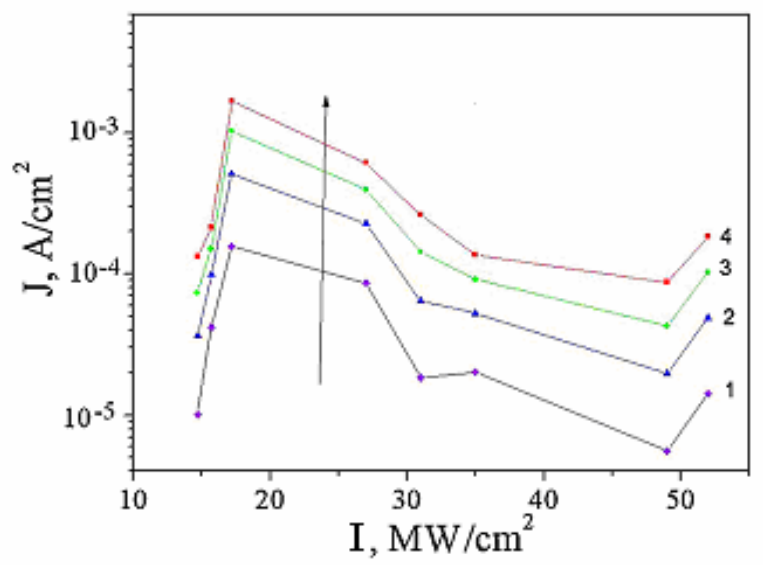

Fig. 5. Density of current through the $\mathrm{SiO}_{\mathrm{x}}$ films versus the intensity of laser irradiation $(\lambda=532 \mathrm{~nm}, t=10 \mathrm{~ns}): E=$ $5 \cdot 10^{4} \mathrm{~V} / \mathrm{cm}(1) ; 1 \cdot 10^{5}(2) ; 1.5 \cdot 10^{5}(3) ; 2 \cdot 10^{5}(4)$.
Initial growth of electrical conductivity at small intensities and the following conductivity decrease with the increase of the laser irradiation intensity is observed. This behavior of the experimental curves can be explained by changes in the number, energy and spatial positions of the electron traps in the film bandgap during laser heating and film structure transformation. At the beginning, the current grows due to generation of additional electron traps in the film. After that, the number of the traps decreases with growth of the laser irradiation intensity [15]. It can be caused by laser annealing of created structural defects.

\section{Conclusion}

The investigations of influence of thermal and laser annealing on $\mathrm{SiO}_{\mathrm{x}}$ film properties have been performed. It has been shown that thermal annealing promotes transformation of silicon-enriched $\mathrm{SiO}_{\mathrm{x}}$ films into nanocomposite $\mathrm{SiO}_{2}(\mathrm{Si})$ films containing $\mathrm{Si}$ nanoislands. The height and surface density of the nanoislands depend on both the silicon content in the initial $\mathrm{SiO}_{\mathrm{x}}$ film and temperature of thermal annealing. The higher annealing temperature causes formation of large nanoislands, but their surface density decreases. Growth of electrical conductivity with thermal annealing temperature was observed.

In the case of laser annealing, it is possible to observe local formation of Si nanoislands on the surface. The intensity of laser irradiation significantly influences on the nanoislands' parameters. At the beginning, at low laser irradiation intensities the $\mathrm{SiO}_{\mathrm{x}}$ film conductivity increases, but the following growth of intensity causes the decrease in electrical conductivity. The comparison of nanoislands created at thermal and laser annealing shows that in case of laser annealing the nanoislands are higher and their surface density is lower.

\section{Acknowledgments}

This research was supported in part by the Project Nos. 1.1.7.30/21-DP and 85/14-H from National Academy of Sciences of Ukraine.

\section{References}

1. E. Fazio, E. Barletta, F. Barreca, and F. Neri, $\mathrm{S}$. Trusso, Investigation of a nanocrystalline silicon phase embedded in $\mathrm{SiO}_{x}$ thin films grown by pulsed laser deposition // J. Vac. Sci. Technol. B, 23, p. 519-522 (2005).

2. A.G. Nassiopoulou, in: H.S. Nalwa (Ed.), Encyclopedia of Nanoscience and Nanochnology, 9, p. 793-813 (2004).

3. H.R. Philipp, Optical properties of non-crystalline $\mathrm{Si}, \mathrm{SiO}, \mathrm{SiO}_{\mathrm{x}}$ and $\mathrm{SiO}_{2} / /$ J. Phys. Chem. Solids, 32, p. 1935-1945 (1971).

4. O.L. Bratus', A.A. Evtukh, V.A. Ievtukh, V.G. Litovchenko, Nanocomposite $\mathrm{SiO}_{2}(\mathrm{Si})$ films as a 
medium for non-volatile memory // J. Non. Cryst. Solids, 354, p. 4278-4281 (2008).

5. C. Pace, F. Crupi, S. Lombardo, C. Gerardi, G. Cocorullo, Room-temperature single-electron effects in silicon nanocrystal memories // Appl. Phys. Lett. 87, 182106 (2005)

6. J. De Castro, F. Lopez, J. Melendez, and M. Fernandez, Optical properties of ion-assisted deposited SiO thin films // Thin Solid Films, 241, p. 202-205 (1993).

7. H. Rinnert, M. Vergnat, G. Marchal, and A. Burneau, Strong visible photoluminescence in amorphous $\mathrm{SiO}_{\mathrm{x}}$ and $\mathrm{SiO}_{\mathrm{x}}: \mathrm{H}$ thin films prepared by thermal evaporation of $\mathrm{SiO}$ powder // J. Lumin. 80, p. 445-448 (1998).

8. E. Desbiens, R. Dolbec, and M. A. El Khakani, Reactive pulsed laser deposition of high-k silicon dioxide and silicon oxynitride thin films for gatedielectric applications // J. Vac. Sci. Technol. A, 20, p. 1157-1161 (2002).

9. M. Lackner, W. Waldhauser, R. Ebner, W. Lenz, C. Suess, G. Jakopic, G. Leising, and H. Hutter, Pulsed laser deposition: a new technique for deposition of amorphous $\mathrm{SiO}_{\mathrm{x}}$ thin films // Surf. Coat. Technol. 163-164, p. 300-305 (2003).

10. C.-J. Lin, G.-R. Lin, Y.-L. Chueh, L.-J. Chou, Synthesis of silicon nanocrystals in silicon-rich $\mathrm{SiO}_{2}$ by rapid $\mathrm{CO}_{2}$ laser annealing // Electrochem. Solid-State Lett. 8, p. D43-D45 (2005).

11. A. Janotta, Y. Dikce, M. Schmidt, C. Eisele, Lightinduced modification of $\mathrm{a}-\mathrm{SiO}_{\mathrm{x}}: \mathrm{H}$. I. Metastability // J. Appl. Phys. 93, p. 4060-4068 (2004).

12. B. Gallas, C.-C. Kao, S. Fisson, G. Vuye, J. Rivory, Y. Bernard, C. Belouet, Laser annealing of $\mathrm{SiO}_{x}$ thin films // Appl. Surf. Sci. 185, p. 317-320 (2002).

13. D. Nesheva, C. Raptis, A. Perakis, I. Bineva, Z. Aneva, Z. Levi, S. Alexandrova, and H. Hofmeister, Raman scattering and photoluminescence from $\mathrm{Si}$ nanoparticles in annealed $\mathrm{SiO}_{\mathrm{x}}$ thin films // J. Appl. Phys. 92, p. 4678-4683 (2002).

14. X.Y. Chen, Y.F. Lu, Y.H. Wu, B.J. Cho, M.H. Liu, D.Y. Dai, and W.D. Song, The mechanisms of photoluminescence from silicon nanocrystals formed by pulsed-laser deposition in argon and oxygen ambient // J. Appl. Phys. 93, p. 6311-6319 (2003).
15. O.O. Gavrylyuk, O.Yu. Semchyk, O.L. Bratus, A.A. Evtukh, O.V. Steblova, L.L. Fedorenko, Study of thermophysical properties of crystalline silicon and silicon-rich silicon oxide layers // Appl. Surf. Sci. 302, p. 213-215 (2014).

16. O.O. Gavrylyuk, O.Yu. Semchyk, O.V. Steblova, A.A. Evtukh, L.L. Fedorenko, Study of the distribution of temperature profiles in nonstoichiometric $\mathrm{SiO}_{\mathrm{x}}$ films at laser annealing // Ukr. J. Phys. 59, p. 712-714 (2014).

17. O.L. Bratus', A.A. Evtukh, O.S. Lytvyn, M.V. Voitovych, V.O. Yukhymchuk, Structural properties of nanocomposite $\mathrm{SiO}_{2}(\mathrm{Si})$ films obtained by ion-plasma sputtering and thermal annealing // Semiconductor Physics, Quantum Electronics \& Optoelectronics, 14(2), p. 247-255 (2011).

18. G.Ya. Krasnikov and N.A. Zaitseva, System Silicon-Silicon Dioxide in Submicron Very Large Integrated Circuits. Technosphere, Moscow, 2003 (in Russian).

19. K. Hubner, Chemical bond and related properties of $\mathrm{SiO}_{2}$. VII. Structure and electronic properties of the $\mathrm{SiO}_{\mathrm{x}}$ region of $\mathrm{Si}-\mathrm{SiO}_{2}$ interfaces // Phys. Status Solidi (a), 61(2), p. 665 (1980).

20. M.Ya. Sushko and S.K. Kryskiv, Method of compact groups in the theory of permittivity of heterogeneous systems // Zhurnal tekhnicheskoi fiziki, 79(3), p. 97 (2009), in Russian.

21. D.E. Aspnes, Optical properties of $\mathrm{Si}$, in: Properties of Crystalline Silicon, Ed. R. Hull. INSPEC IEE, London, 1999, p. 677.

22. A. Lehmann, L. Schumann, K. Hubner. Optical phonons in amorphous silicon oxides // Phys. Status Solidi (b), 151, p. 317-323 (1987).

23. I.P. Lisovskii, V.G. Litovchenko, V.B. Lozinskii, S.I. Frolov, H. Flietner, W. Fussel, E. Schmidt, IR study of short-range and local order in $\mathrm{SiO}_{2}$ and $\mathrm{SiO}_{\mathrm{x}}$ films // J. Non-Cryst. Solids, 187, p. 91 (1995).

24. M.C. Rossi, S. Salvatori, M. Burchielli, G. Conte, Optical and electrical properties of silicon nanocrystals formed by $\mathrm{CW}$ laser irradiation of amorphous silicon oxides // Thin Solid Films, 383, p. $267-270$ (2001). 